\title{
Restarting elective endoscopy safely amidst an evolving pandemic and the impact of patient perception
}

\author{
Christopher Nguyen ${ }^{1 *} \mathbb{0}$, Kevin T. Kline ${ }^{2}$, Shehzad Merwat ${ }^{2}$, Sheharyar Merwat ${ }^{2}$, Gurinder Luthra², \\ Sreeram Parupudi ${ }^{2}$ and Steven Cohn ${ }^{2}$
}

\begin{abstract}
Background: The COVID-19 pandemic has led to disruptions in elective and outpatient procedures. Guidance from the Centers for Medicare and Medicaid Services provided a framework for gradual reopening of outpatient clinical operations. As the infrastructure to restart endoscopy has been more clearly described, patient concerns regarding viral transmission during the procedure have been identified. Moreover, the efficacy of the measures in preventing transmission have not been clearly delineated.

Methods: We identified patients with pandemic-related procedure cancellations from 3/16/2020 to 4/20/2020. Patients were stratified into tier groups (1-4) by urgency. Procedures were performed using our hospital risk mitigation strategies to minimize transmission risk. Patients who subsequently developed symptoms or tested for COVID-19 were recorded.

Results: Among patients requiring emergent procedures, $57.14 \%$ could be scheduled at their originally intended interval. COVID-19 concerns represented the most common rescheduling barrier. No patients who underwent postprocedure testing were positive for COVID-19. No cases of endoscopy staff transmission were identified.

Conclusions: Non-COVID-19 related patient care during the pandemic is a challenging process that evolved with the spread of infection, requiring dynamic monitoring and protocol optimization. We describe our successful model for reopening endoscopy suites using a tier-based system for safe reintroduction of elective procedures while minimizing transmission to patients and staff. Important barriers included financial and transmission concerns that need to be addressed to enable the return to pre-pandemic utilization of elective endoscopic procedures.
\end{abstract}

Keywords: COVID-19, Pandemic, Endoscopy, Re-opening, Patient perception

\section{Background}

Since the first documented case of COVID-19 in the United States (US) on January 21, 2020, many hospitals have had to enact strict measures to prevent further spread of the virus among the population. The pandemic

\footnotetext{
*Correspondence: chmnguye@utmb.edu

1 Department of Internal Medicine, University of Texas Medical Branch, John Sealy Annex, 301 University BoulevardRoom 4.108, Galveston, TX 77555, USA

Full list of author information is available at the end of the article
}

has led to widespread disruptions in the performance of elective and outpatient procedures. Endoscopic procedures were especially affected by these disruptions due to high rates of aerosolization of the virus by upper endoscopy, viral shedding in the stool, and potential contamination of endoscopy suite surfaces with viable virus up to $72 \mathrm{~h}$ after initial contact [1]. As endoscopic procedures also carry a high risk of viral spread to healthcare providers, it became necessary for hospitals to set up an organized model for re-opening endoscopy suites to elective 
procedures through a combination of testing, triage, and provision of appropriate personal protective equipment to patients and staff. Little is currently known regarding the efficacy of these measures in preventing transmission of the novel virus to staff and patients in this context. Since patient perception of procedure associated infection has been identified as a significant concern when restarting outpatient elective procedures, it is crucial to assess the safety of our procedures to ensure ongoing appropriate utilization of outpatient endoscopy [2].

As of the date of this manuscript, there have been over 33 million confirmed cases of COVID-19 in the United States out of 173 million cases worldwide with over 3.5 million COVID-19 related deaths worldwide [3]. The infectious transmission of the virus is thought to be via respiratory droplets with potential for airborne spread during aerosol-producing procedures, such as endoscopy [4]. The insidious nature of the epidemic stems from its high rate of asymptomatic spread, with $80 \%$ of cases being mild or asymptomatic [4]. Considering this, the US Surgeon General recommended the cancellation of all elective procedures on March 14, 2020 [5]. Soon after on March 17, 2020, the American College of Surgeons, American Gastroenterological Association (AGA), and the other national gastroenterology societies recommended rescheduling elective procedures to focus only urgent and emergent endoscopic procedures [6-8].

The first inpatient case of COVID-19 at our institution was confirmed on March 3, 2020. As the number of inpatient cases increased, the capacity to safely perform invasive procedures decreased with limited guidance regarding appropriate re-opening strategies and stratification of endoscopic cases from the joint GI societies [9, 10]. As the prevalence of disease became more clearly established by widespread testing within our institution and community, the Division of Gastroenterology and Hepatology developed a tiered strategy in an effort to resume timely scheduling of patients awaiting diagnostic procedures. The Centers for Medicare and Medicaid Services (CMS), in concordance with multi-society guidelines, helped provide a framework for gradual reopening of outpatient clinical procedures. Here we describe the process and outcomes of a tier-based system for scheduling outpatient endoscopy, in the context of an ongoing, and evolving pandemic, to provide diagnostic and screening endoscopy services within a reasonable period applying appropriate risk mitigation precautions for patients and staff members. In addition, within the context of those needing urgent procedures we identified barriers to proceeding with endoscopy. Despite the absence of procedural COVID-19 transmission at our institution, concerns voiced by patients provided important insight into challenges the gastroenterology community will have to address in the immediate future and beyond.

\section{Methods}

Using the EPIC electronic medical record (EMR), patients with cancelled procedures due to the COVID-19 pandemic from 3/16/2020 to 4/20/2020 were identified from two separate practice locations within our medical system, the University of Texas Medical Branch (UTMB) endoscopy unit in Galveston and the UTMB League City campus endoscopy unit. Patients were stratified into tier groups (1-4) by gastroenterology faculty in order of urgency (Table 1). During phase 1 of Texas's reopening, tier 1 (urgent/emergent) and tier 2 (semi-urgent) cases were identified and reviewed by the newly formed Endoscopy Committee and, if approved, were contacted by the nursing staff and scheduled within 1 week and 4 weeks respectively. During phase 2 , tier 3 and 4 cases were to be rescheduled within 3 months. After the initial scheduling, the barriers to successful rescheduling were assessed and organized by the nursing staff (Table 2). Within a short period after the initiation of the tier system, once the urgent and semi-urgent cases were scheduled, due to increase surge capacity all tiers were eventually accommodated at the patient's earliest convenience.

Our hospital risk mitigation strategies included a strict no visitor policy, temperature and symptom screening of all hospital employees at the entrance to the hospital, mandating the use of masks in all patient care areas of the hospital, maintaining 6 feet of social distancing, and mandatory testing of all inpatients for COVID-19 as well as COVID-19 testing for all health care providers

Table 1 Tier system

\begin{tabular}{lll}
\hline Tier & Criteria & Timing \\
\hline 1 & Abnormal imaging, rapid weight loss, dehydration due to Gl symptoms, ongoing Gl bleeding, acute dysphagia & Within 1 week \\
2 & $\begin{array}{c}\text { Chronic diarrhea, chronic dysphagia, chronic anemia, Post-polypectomy/resection follow up, variceal screening with } \\
\text { history of bleed }\end{array}$ & Within 4 weeks \\
3 & Barrett's follow up/surveillance, variceal screening without bleed, IBD surveillance & Within 3 months \\
4 & Screening or surveillance procedures for polyps without any alarm signs & After 3 months \\
\hline
\end{tabular}

Tier system to prioritize rescheduling outpatient endoscopy procedures consisting of the criteria for each tier and their respective rescheduling time frame goals 
Table 2 Endoscopy rescheduling due to COVID-19 pandemic

\begin{tabular}{|c|c|c|c|c|}
\hline Tier & $1(n=16)$ & $2(n=170)$ & $3(n=140)$ & $4(n=214)$ \\
\hline Total reached by phone & $14(87.50 \%)$ & $147(86.47 \%)$ & $105(75 \%)$ & $120(56.07 \%)$ \\
\hline Total rescheduled & 8 & 72 & 62 & 85 \\
\hline \multicolumn{5}{|l|}{ Rescheduling timing } \\
\hline Within 1 week & 2 & 51 & 17 & 5 \\
\hline Within 4 weeks & 5 & 19 & 42 & 63 \\
\hline After 4 weeks & 1 & 2 & 3 & 17 \\
\hline \multicolumn{5}{|c|}{ Reasons for not rescheduling } \\
\hline COVID-19 concerns & 3 & 30 & 30 & 25 \\
\hline Financial & 0 & 6 & 4 & 0 \\
\hline Transport & 0 & 9 & 3 & 0 \\
\hline Other & 3 & 30 & 15 & 7 \\
\hline COVID-19 positive & 0 & 1 & 0 & 0 \\
\hline
\end{tabular}

Number of patients successfully rescheduled within their respective time frame goals in addition to patients who deferred rescheduling and the reasons for deferment

involved in endoscopy patient care. In the endoscopy unit, comprehensive personal protective equipment (PPE) protocols were developed based on national and international guidance and experience including: head coverings, gowning, N95 masks for all staff during endoscopy (with mandate for prior fit testing performed) in addition to an overlying surgical mask, eye protection, and double gloving. Specific doffing and donning techniques with hand hygiene were implemented and quality checks by staff were enforced $[11,12]$. Enhanced cleaning techniques were implemented for each active endoscopy suite between cases, with increased time between scheduled cases to account for these measures. All patients underwent pre-procedure COVID-19 testing within $72 \mathrm{~h}$ of their scheduled procedure with polymerase chain reaction (PCR) test, or rapid testing on day of procedure, if unable to be screened prior. Both were administered and processed at our institution. In addition, all patients were screened for COVID-19 symptoms on the day of procedure at admission with a plan to reschedule anyone with a positive COVID-19 test or suggestive symptoms.

Patients who had completed their respective endoscopic procedures were contacted by telephone to inquire if they underwent COVID-19 testing within 14 days postprocedure (Table 3 ). The symptoms experienced at the time, reason for testing, and results of the testing were assessed to evaluate the efficacy of peri-procedural transmission prevention measures.

\section{Results}

Of the 540 patients awaiting delayed endoscopic procedures between 3/16/2020 to $4 / 20 / 2020$ due to the pandemic, 227 patients across all tiers were rescheduled. Of these, only $57.14 \%$ of tier 1 and $48.97 \%$ of tier 2 could be scheduled at their originally intended procedure interval, respectively. Even with the capability to accommodate for all tier 1 and tier 2 patients, the average delay of endoscopy from the initial scheduled procedure date to index endoscopy was 32 days, with the longest delay being 86 days. Despite counseling on extensive safety measures instituted as well as the indication for the procedure, the most identified barrier for patients to return to undergo urgent or semi-urgent endoscopy was COVID-19 related concerns in $40 \%$ of tier 1 and tier 2 patients. $7.2 \%$ of patients in the same cohort identified new financial limitations as reasons for not scheduling. Patient refusals while scheduling Tiers 1 \& 2 allowed prompt scheduling of majority of the other tiers early. Our pre-procedure COVID-19 testing of the patients willing to return for their procedures revealed a seroprevalence of $1.3 \%$, which is lower than the test positivity of $4.4 \%$ in the general population of Galveston county at the same time and continued to rise even after the conclusion of our study.

Of the 281 patients who underwent their re-scheduled endoscopic procedures (Table 3), 94.7\% of patients received the rapid molecular diagnostic test (Rapid ID Now) and 5.3\% of patients received the PCR test. The average number of days patients were tested prior to their procedures was 2 days. $24 \%$ of patients who underwent upper endoscopies and $3.7 \%$ of those who underwent lower endoscopies were tested again during post-procedure follow up either due to newonset symptoms suspicious for COVID-19 infection, or requiring hospitalization for unrelated reasons, or needing medical clearance prior to follow-up procedure. Of the patients who were symptomatic, fever, cough and gastrointestinal symptoms were the most reported. None of the patients who underwent 
Table 3 Pre and post-procedure COVID-19 testing

\begin{tabular}{|c|c|c|c|c|c|c|c|c|c|c|c|}
\hline Procedure & Rapid ID & PCR & $\begin{array}{l}\text { Days } \\
\text { before } \\
\text { procedure }\end{array}$ & Fever & Cough & SOB & $\begin{array}{l}\text { Anosmia/ } \\
\text { Ageusia }\end{array}$ & Gl symptoms & $\begin{array}{l}\text { Responded } \\
\text { to survey }\end{array}$ & Postop testing & $n$ \\
\hline EGD & $92.4 \%(61)$ & $\begin{array}{l}7.6 \% \\
(5)\end{array}$ & 2.0 days & $\begin{array}{l}3.0 \% \\
(2)\end{array}$ & $\begin{array}{l}13.6 \% \\
(9)\end{array}$ & $\begin{array}{l}7.6 \% \\
(5)\end{array}$ & $\begin{array}{l}1.5 \% \\
(1)\end{array}$ & $\begin{array}{l}7.6 \% \\
(5)\end{array}$ & $\begin{array}{l}90.9 \% \\
(60)\end{array}$ & $\begin{array}{l}25.8 \% \\
(17)\end{array}$ & 66 \\
\hline ERCP & $\begin{array}{l}100 \% \\
(11)\end{array}$ & 0 & 1.2 days & 0 & 0 & $\begin{array}{l}9.1 \% \\
(1)\end{array}$ & 0 & $\begin{array}{l}27.3 \% \\
(3)\end{array}$ & $\begin{array}{l}72.7 \% \\
(8)\end{array}$ & $\begin{array}{l}27.3 \% \\
(3)\end{array}$ & 11 \\
\hline EUS & $\begin{array}{l}100 \% \\
(2)\end{array}$ & 0 & 2.0 days & 0 & $\begin{array}{l}50 \% \\
(1)\end{array}$ & $\begin{array}{l}50 \% \\
(1)\end{array}$ & $\begin{array}{l}50 \% \\
(1)\end{array}$ & 0 & $\begin{array}{l}100 \% \\
(2)\end{array}$ & 0 & 2 \\
\hline EUS/ERCP & $\begin{array}{l}83.3 \% \\
(5)\end{array}$ & $\begin{array}{l}16.7 \\
(1)\end{array}$ & 1.7 days & 0 & $\begin{array}{l}33.3 \% \\
(2)\end{array}$ & $\begin{array}{l}16.7 \\
(1)\end{array}$ & 0 & 0 & $\begin{array}{l}50 \% \\
(3)\end{array}$ & $\begin{array}{l}16.7 \\
(1)\end{array}$ & 6 \\
\hline Enteroscopy & $\begin{array}{l}100 \% \\
(1)\end{array}$ & 0 & 1 & 0 & $\begin{array}{l}100 \% \\
(1)\end{array}$ & $\begin{array}{l}100 \% \\
(1)\end{array}$ & 0 & 0 & $\begin{array}{l}100 \% \\
(1)\end{array}$ & 0 & 1 \\
\hline PEG & $(1)$ & 0 & 1 & & & & & & 0 & 0 & 1 \\
\hline Total Upper Endoscopies & $\begin{array}{l}93 \% \\
(81)\end{array}$ & $\begin{array}{l}7 \% \\
\text { (6) }\end{array}$ & 1.8 & $\begin{array}{l}2.3 \% \\
(2)\end{array}$ & $\begin{array}{l}14.9 \% \\
(13)\end{array}$ & $\begin{array}{l}10.3 \% \\
(9)\end{array}$ & $\begin{array}{l}2.6 \% \\
(2)\end{array}$ & $\begin{array}{l}9.2 \% \\
(8)\end{array}$ & $\begin{array}{l}85.1 \% \\
(74)\end{array}$ & $\begin{array}{l}24.1 \% \\
(21)\end{array}$ & 87 \\
\hline Colonoscopy & $\begin{array}{l}94.7 \% \\
(124)\end{array}$ & $\begin{array}{l}5.3 \% \\
(7)\end{array}$ & 2.1 days & $\begin{array}{l}0.8 \% \\
(1)\end{array}$ & $\begin{array}{l}1.6 \% \\
(2)\end{array}$ & $\begin{array}{l}0.8 \% \\
(1)\end{array}$ & 0 & $\begin{array}{l}3.1 \% \\
(4)\end{array}$ & $\begin{array}{l}88.5 \% \\
(116)\end{array}$ & $\begin{array}{l}3.8 \% \\
(5)\end{array}$ & 131 \\
\hline Ileoscopy & $\begin{array}{l}100 \% \\
(1)\end{array}$ & 0 & 2 & 0 & 0 & 0 & 0 & 0 & $100 \%$ & 0 & 1 \\
\hline Flex sig & $\begin{array}{l}100 \% \\
(2)\end{array}$ & 0 & 2 & 0 & 0 & 0 & 0 & 0 & $\begin{array}{l}50 \% \\
(1)\end{array}$ & 0 & 2 \\
\hline Total Lower Endoscopies & $\begin{array}{l}96.3 \% \\
(129)\end{array}$ & $\begin{array}{l}4.0 \% \\
(7)\end{array}$ & 2.1 & $\begin{array}{l}0.7 \% \\
(1)\end{array}$ & $\begin{array}{l}1.5 \% \\
(2)\end{array}$ & $\begin{array}{l}0.7 \% \\
(1)\end{array}$ & 0 & $\begin{array}{l}3.0 \% \\
(4)\end{array}$ & $\begin{array}{l}87.3 \% \\
(117)\end{array}$ & $\begin{array}{l}3.7 \% \\
(5)\end{array}$ & 134 \\
\hline EGD/Colon & $\begin{array}{l}96.7 \% \\
(58)\end{array}$ & $\begin{array}{l}3.3 \% \\
(2)\end{array}$ & 2.1 days & $\begin{array}{l}1.67 \% \\
(1)\end{array}$ & $\begin{array}{l}10 \% \\
(6)\end{array}$ & $\begin{array}{l}6.7 \% \\
(4)\end{array}$ & 0 & $\begin{array}{l}1.67 \% \\
(1)\end{array}$ & $\begin{array}{l}73.3 \% \\
(44)\end{array}$ & $\begin{array}{l}18.3 \% \\
(11)\end{array}$ & 60 \\
\hline All & $\begin{array}{l}94.7 \% \\
(266)\end{array}$ & $\begin{array}{l}5.3 \% \\
(15)\end{array}$ & 2.0 & $\begin{array}{l}1.4 \% \\
(4)\end{array}$ & $\begin{array}{l}7.5 \% \\
(21)\end{array}$ & $\begin{array}{l}5 \% \\
(14)\end{array}$ & $\begin{array}{l}0.7 \% \\
(2)\end{array}$ & $\begin{array}{l}4.6 \% \\
(13)\end{array}$ & $\begin{array}{l}87.5 \% \\
(246)\end{array}$ & $\begin{array}{l}13.2 \% \\
(37)\end{array}$ & 281 \\
\hline
\end{tabular}

Total procedures performed stratified by type of procedure. Pre-operative and post-operative COVID-19 test results were recorded

post-procedure testing were positive for COVID-19. Of the 4 patients that reported fever after endoscopy, 3 of the patients tested negative for COVID-19 by rapid assay. One patient declined testing because fever resolved within $24 \mathrm{~h}$. During the study period, no cases of endoscopy unit transmission to staff were identified.

Of the patients in tier 1 and tier 2 who successfully underwent rescheduled endoscopy, 4 patients were diagnosed with a gastrointestinal malignancy or inflammatory bowel disease. These cases consisted of gastric adenocarcinoma, esophageal adenocarcinoma, ulcerative colitis, and Crohn's disease. The average delay of endoscopy in these 4 patients was 34 days from the initial scheduled procedure date to the index endoscopy. The patient with gastric adenocarcinoma passed away within 1 month of diagnosis. The patient with Crohn's disease was listed as deceased within 3 months of diagnosis for unclear reasons and occurred outside the confines of our electronic medical record. No significant interim upper or lower gastrointestinal bleeds were identified.

\section{Discussion}

In an attempt to preserve hospital beds, resources, PPE and to protect staff and patients during the COVID-19 pandemic, non-emergent endoscopies were delayed or canceled leading to a substantial reduction in procedures performed in endoscopy suites. Use of our model for reopening endoscopy suites by a tier-based system allowed recognition of barriers for scheduling and facilitated appropriate utilization of the excess capacity to accommodate most patients across all tiers within 4 weeks. Thus, minimizing delays in patient care.

By practicing our strict risk mitigation strategies, which were in line with experiences and practice in Italy implicating low risk of transmission during endoscopy if the proper precautions are taken, we were able to limit the peri-procedure transmission to nil as shown by the data from our post-procedure surveys (Table 3) [13, 14]. Despite these successes, the barriers to restarting endoscopy in our study remain the public perception of safety in addition to the financial cost and loss of insurance coverage during the pandemic. This narrowed the utility of 
our tier system, as our highest priority patients identified COVID-19 related unemployment and financial limitations besides peri-procedure infection concerns as reasons for postponing their procedures. While COVID-19 related concerns accounted for the largest proportion of patients in all groups, a financial disparity was noted in comparison to our Tier 4 patients (most often average risk colon cancer screening colonoscopies), none of whom reported insurance or cost concerns for reasons for postponement. Interestingly, our reported rates of COVID-19 concern related postponement in procedures are much higher than the rates reported by Rex et al., where only $4.3 \%$ were unwilling to undergo elective endoscopy in May 2020 versus 16.3\% across all tiers in our cohort [2]. Partly this difference is likely related to relative lower socioeconomic status of our main hospital's catchment area, Galveston County, including a $12.9 \%$ poverty rate prior to the pandemic. Individuals with lower incomes and education perceive higher personal health and financial threats from COVID-19 compared to other groups [15]. This may explain this disparity, particularly at the beginning of the pandemic when infection burden in our area was relatively low compared to other parts of the country. Relatively slower peaking of the infection rates in the region led to a situation where public perception and fear played a role in some delay in resuming the procedural services. Implementation of safety measures with a robust testing capacity and easy access for patients and endoscopy staff as well as appropriate planning for adequate supplies of PPE from the onset and throughout allowed relatively high overall number of patients to eventually undergoing endoscopic procedures during this period. While the tiered approach for rescheduling and higher patient response rate for survey after the procedures are the strengths of the study, the limitations include relatively lower number of Tier 1 and Tier 4 patients who could be rescheduled. After initial testing, lack of serial formal COVID-19 testing for endoscopy staff during the study period is another potential limitation to detect asymptomatic transmission.

Suspending non-urgent endoscopic procedures has serious clinical and financial implications. Approximately 18 million endoscopic procedures are performed annually in the US with an estimated annual healthcare cost of $\$ 32.4$ billion $[16,17]$. The consequences of suspending elective endoscopy for even 6 months has grim medical implications including the impediment of surveilling nearly 1,500 fatal but preventable variceal bleeds in cirrhotic patients [18-20]. Additionally, there could be a delay in the diagnosis of nearly 22,000 high grade adenomatous polyps with malignant potential and 3000 colorectal cancers, resulting in a $6.5 \%$ increase in the 6-month mortality rate for patients who would eventually be diagnosed with colorectal cancer [17, 21, 22]. Our study identified delays in the diagnosis of 2 gastrointestinal malignancies and 2 cases of inflammatory bowel disease in patients with the highest priority in endoscopy. A recent study estimated a 58\% decrease in weekly cancer detections and up to a 95\% decrease in endoscopic activity during the height of the COVID-19 pandemic when compared to pre-COVID-19 activity [23]. It is therefore important to methodically recommence non-emergent endoscopy to minimize the economic and health impacts of its suspension.

With the progression of the COVID-19 pandemic, multiple best practice guidelines have emerged regarding pre-procedure, peri-procedure, and post-procedure risk mitigation strategies. One particular study analyzed the consensus of effectiveness of these strategies among multi-national large endoscopy departments using a modified Delphi method [24]. Many of the high consensus recommendations were in-line with the mitigation strategies performed at our institution. Other recent studies have detailed the most cost-effective strategies of pre-procedure testing and risk stratification including similar use of telephone screening methods as in our study $[24,25]$.

To conclude, our tiered approach for rescheduling while following strict risk mitigation strategies allowed for successfully resuming outpatient endoscopic procedures keeping patients as well as endoscopy staff safe and protected from COVID-19 transmission. Patients who opted to proceed with their procedures were successfully accommodated with 15 min additional time allotted to room cleaning and turnover per case. Additionally, our mitigation measures resulted in no transmission of COVID-19 cases that could be traced back to exposure during endoscopy. Future studies regarding procedural transmission of COVID-19 in the asymptomatic population may further allay patient fears. However, the financial impact of this pandemic will continue to be a stubborn remnant from this novel virus, delaying patient care and impacting utilization of endoscopy in the future.

\section{Conclusion}

By implementing a tiered approach to reschedule patients undergoing elective endoscopy during the height of the COVID-19 pandemic with strict risk mitigation strategies, our institution was able to safely restart outpatient endoscopy to minimize delays in endoscopic diagnosis and patient care. All patients deemed higher risk that were willing to undergo endoscopy were accommodated for. The main barrier to rescheduling was public perception of safety. The risk mitigation measures taken allowed for zero transmission of COVID-19 among patients and staff members. 


\begin{abstract}
Abbreviations
AGA: American Gastroenterological Association; CMS: Centers for Medicaid and Medicare Services; EGD: Esophagogastroduodenoscopy; EMR: Electronic Medical Record; GI: Gastroenterology; PCR: Polymerase Chain Reaction; PPE: Personal Protective Equipment; US: United States; UTMB: University of Texas Medical Branch.
\end{abstract}

\section{Acknowledgements}

The authors would like to acknowledge and thank Lance Watson and McKenzie Sheridan for their assistance in this study.

\section{Authors' contributions}

Conception and design: K.K., S. C., S. M., S. M., S. P. Analysis and interpretation of the data: C. N., K. K., S. M., S.M. Drafting of the article: C. N., K. K. Critical revision of the article for important intellectual content: S. P., S. C., S.M., S. M. Final approval of the article: All authors contributed equally. All authors read and approved the final manuscript.

\section{Funding}

There are no financial disclosures nor any funding or financial support received.

\section{Availability of data and materials}

The patients in our study have not been reported in any other submission. The data can be accessed via the links to a repository provided below: https://figsh are.com/s/e63ad2152c81c9f8abe4, https://figshare.com/s/68fef52c0c03804 f05f3, https://figshare.com/s/770d244fa95c70332737.

\section{Declarations}

\section{Ethics approval and consent to participate}

The study was deemed institutional review board exempt by the University of Texas Medical Branch review board criteria due to the quality improvement nature of the study.

\section{Consent for publication}

Not applicable.

\section{Competing interests}

There are no conflicts of interest or competing interests that the authors would like to report.

\section{Author details}

1 Department of Internal Medicine, University of Texas Medical Branch, John Sealy Annex, 301 University BoulevardRoom 4.108, Galveston, TX 77555, USA. ${ }^{2}$ Division of Gastroenterology and Hepatology, University of Texas Medical Branch, Galveston, TX, USA

Received: 28 October 2020 Accepted: 27 August 2021

Published online: 06 September 2021

\section{References}

1. van Doremalen N, Bushmaker T, Morris DH, et al. Aerosol and surface stability of SARS-CoV-2 as compared with SARS-CoV-1. N Engl J Med.

2. Rex DK, Vemulapalli KC, Kane MJ, McHenry L, Sherman S, Al-Haddad M. Most patients are willing to undergo elective endoscopic procedures during the reopening period of the COVID-19 pandemic. Gastroenterology.

3. National Center for Immunization and Respiratory Diseases DoVD. Cases in the US. https://www.cdc.gov/coronavirus/2019-ncov/cases-updates/casesin-us.html. Published 2020. Accessed May 24, 2020.

4. Cevik M, Bamford C, Ho A. COVID-19 pandemic-A focused review for clinicians. Clin Microbiol Infect.

5. Adams J. Please consider stopping elective procedures. https://twitter.com/ surgeon_general/status/1238798972501852160?lang=en. Published 2020. Accessed June 6, 2020

6. Surgeons ACo. COVID-19: recommendations for management of elective surgical procedures. https://www.facs.org/about-acs/covid19/infor mation-forsurgeons/elective-surgery. Published 2020. Accessed June 6, 2020.

7. Sultan S, Lim JK, Altayar O, et al. AGA Institute rapid recommendations for gastrointestinal procedures during the COVID-19 pandemic. Gastroenterology. 2020.

8. Joint GI Society Message on COVID-19. https://gi.org/2020/03/15/joint-gisocietymessage-on-covid-19/. Published 2020. Accessed June 6, 2020.

9. Bilal M, Simons M, Rahman AU, et al. What constitutes urgent endoscopy? A social media snapshot of gastroenterologists' views during the COVID-19 pandemic. Endosc Int Open. 2020;8(5):E693-8.

10. Sawhney MS, Bilal M, Pohl H, et al. Triaging advanced Gl endoscopy procedures during the COVID-19 pandemic: consensus recommendations using the Delphi method. Gastrointest Endosc. 2020.

11. Raju G. Wearing and removing PPE during COVID-19. https://twitter.com/ gsraju1/status/1243024120973004800. Published 2020. Accessed June 11, 2020.

12. Repici A, Maselli R, Colombo M, et al. Coronavirus (COVID-19) outbreak: what the department of endoscopy should know. Gastrointest Endosc. 2020.

13. Repici A, Aragona G, Cengia G, et al. Low risk of covid-19 transmission in Gl endoscopy. Gut. 2020.

14. Leonardo MG, Manuel MS, Cristiano S. A safe endoscopy during COVID-19 pandemia. Gastrointest Endosc. 2020.

15. Understanding America Study Comprehensive File. Understanding Coronavirus in America. https://uasdata.usc.edu/page/UAS+Comprehensive+ Data+File. Published 2020. Accessed May 24, 2020.

16. Peery AF, Dellon ES, Lund J, et al. Burden of gastrointestinal disease in the United States: 2012 update. Gastroenterology. 2012;143(5):1179-1187.e1173.

17. Peery AF, Crockett SD, Murphy CC, et al. Burden and cost of gastrointestinal, liver, and pancreatic diseases in the United States: update 2018. Gastroenterology. 2019;156(1):254-272.e211.

18. Kleber G, Sauerbruch T, Ansari H, Paumgartner G. Prediction of variceal hemorrhage in cirrhosis: a prospective follow-up study. Gastroenterology. 1991;100(5 Pt 1):1332-7.

19. Varices NIECftSaToE. Prediction of the first variceal hemorrhage in patients with cirrhosis of the liver and esophageal varices. A prospective multicenter study. N Engl J Med. 1988;319(15):983-989.

20. Lay CS, Tsai YT, Lee FY, et al. Endoscopic variceal ligation versus propranolol in prophylaxis of first variceal bleeding in patients with cirrhosis. J Gastroenterol Hepatol. 2006;21 (2):413-9.

21. Fernández-de Castro JD, Baiocchi Ureta F, Fernández González R, Pin Vieito N, Cubiella FJ. The effect of diagnostic delay attributable to the healthcare system on the prognosis of colorectal cancer. Gastroenterol Hepatol. 2019;42(9):527-33.

22. Gupta S, Shahidi N, Gilroy N, Rex DK, Burgess NG, Bourke MJ. Proposal for the return to routine endoscopy during the COVID-19 pandemic. Gastrointest Endosc. 2020.

23. Rutter MD, Brookes M, Lee TJ, Rogers P, Sharp L. Impact of the COVID-19 pandemic on UK endoscopic activity and cancer detection: a National Endoscopy Database Analysis. Gut. 2021;70(3):537-43. https://doi.org/10. 1136/gutjinl-2020-322179.

24. Bhandari P, Subramaniam S, Bourke MJ, Alkandari A, Chiu PWY, Brown JF, Keswani RN, Bisschops R, Hassan C, Raju GS, Muthusamy VR, Sethi A, May GR, Albéniz E, Bruno M, Kaminski MF, Alkhatry M, Almadi M, Ibrahim M, Emura F, Moura E, Navarrete C, Wulfson A, Khor C, Ponnudurai R, Inoue H, Saito Y, Yahagi N, Kashin S, Nikonov E, Yu H, Maydeo AP, Reddy DN, Wallace MB, Pochapin MB, Rösch T, Sharma P, Repici A. Recovery of endoscopy services in the era of COVID-19: recommendations from an international Delphi consensus. Gut. 2020;69(11):1915-24. https://doi.org/10.1136/ gutjil-2020-322329.

25. Hayee B; SCOTS project group, East J, Rees CJ, Penman I. Multicentre prospective study of COVID-19 transmission following outpatient GI endoscopy in the UK. Gut. 2021;70(5):825-828. https://doi.org/10.1136/ gutjinl-2020-322730

\section{Publisher's Note}

Springer Nature remains neutral with regard to jurisdictional claims in published maps and institutional affiliations. 